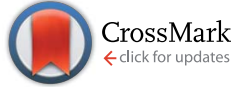

Cite this: RSC Adv., 2016, 6, 20399

Received 4th December 2015 Accepted 5th February 2016

DOI: $10.1039 / c 5 r a 25880 d$

www.rsc.org/advances

\section{Generation of open-ended, worm-like and graphene-like structures from layered spherical carbon materials $\uparrow$}

\author{
Bridget K. Mutuma, ${ }^{a}$ Boitumelo Matsoso, ${ }^{a}$ Kamalakannan Ranganathan, ${ }^{a}$ \\ Daniel Wamwangi ${ }^{b}$ and Neil J. Coville*a
}

\begin{abstract}
A study of the effects of size dispersion of $\mathrm{Au} \mathrm{aSiO}_{2}$ spheres and silica sphere templates for the synthesis of hollow carbon structures was evaluated using a chemical vapor deposition (CVD) nanocasting method. The diameter of the template, the presence of the gold nanoparticles and the polyvinylpyrrolidone (to cap the $\mathrm{Au}$ particles) were found to determine the size, thickness and shape of the synthesized carbon nanostructures. The Auamonodispersed small-sized silica sphere $(80-110 \mathrm{~nm})$ template covered with carbon followed by removal of silica produced broken hollow carbon spheres, whereas an equivalent Auamonodispersed large-sized silica sphere (110-150 nm) template produced hollow carbon spheres with a complete carbon shell. Monodispersed and polydispersed pristine silica spheres without Au produced hollow carbon spheres with complete and deformed carbon shells, respectively. Polyvinylpyrrolidone addition to polydispersed $\mathrm{SiO}_{2}$ spheres, followed by carbonization with toluene $(1 \mathrm{~h})$ and $\mathrm{SiO}_{2}$ removal, produced wormlike carbon structures. Carbonization (and $\mathrm{SiO}_{2}$ removal) of Auapolydispersed silica spheres for a short carbonization time (1 h) gave a layered carbon nanosheet while at intermediate and longer carbonization times (2-4 h) gave nanotube-like (or worm-like) carbon structures. Raman spectra confirmed the formation of the graphitic nature of the carbon materials. These results highlight the potential use of Au@carbon coreshell structures for the generation of few layered graphene-like unusual nanostructures. As a proof of concept, the wormlike carbon structures were incorporated in organic solar cells and found to give a measurable photovoltaic response.
\end{abstract}

\section{Introduction}

Layered graphene structures can in principle be made by two approaches - by a bottom-up approach from carbon building blocks or by top-down approaches from layered carbon materials. The bottom-up approach entails the synthesis of graphene structures by epitaxial growth of graphene sheets through Diels-Alder polymerization, ${ }^{\mathbf{1}, 2}$ layer by layer assembly, ${ }^{3}$ solvothermal $^{4}$ and chemical vapor deposition methods. The chemical vapor deposition (CVD) methodology can entail depositing carbon on a metal template with some or limited carbon solubility such as $\mathrm{Cu},{ }^{5-7} \mathrm{Ni},{ }^{8,9}$ and $\mathrm{Co}^{10}$ among others. The metal template acts as a catalyst for graphene layer formation and growth. In some cases, a catalyst free plasma

${ }^{a}$ DST-NRF Centre of Excellence in Strong Materials and Molecular Sciences Institute, School of Chemistry, University of the Witwatersrand, WITS 2050, Johannesburg, South Africa. E-mail: Neil.coville@wits.ac.za; Fax: +27 117176749

${ }^{b}$ DST-NRF Centre of Excellence in Strong Materials and Materials Physics Research Institute, School of Physics, University of the Witwatersrand, WITS 2050, Johannesburg, South Africa

$\uparrow$ Electronic supplementary information (ESI) available. See DOI: $10.1039 / \mathrm{c} 5 \mathrm{ra} 25880 \mathrm{~d}$ enhanced chemical vapor deposition method, has been used to produce carbon nanosheets and vertically oriented graphene sheets. ${ }^{\mathbf{1 1 - 1 5}}$ The top-down approach involves the exfoliation of graphite by mechanical, electrochemical or chemical means to give graphene. ${ }^{\mathbf{1 6 , 1 7}}$ Indeed, the classical methodology to make graphene is from graphite. ${ }^{\mathbf{1 8}}$ In principle any carbon source (planar, non-planar geometries) that contain layers of carbon atoms could be converted to an open layered carbon material. For instance, unzipping multiwalled carbon nanotubes can result in the formation of graphene oxide nanoribbons ${ }^{19}$ and graphene nanoribbons. ${ }^{20}$ A recent report has indicated that $\mathrm{C}_{60}$ can be converted into graphene quantum dots showing the possibility of creating graphene like structures from spherical carbon materials. $^{21}$

Typically, carbon nanomaterials are classified based on their dimensionalities such as zero-dimensional fullerenes (0D), onedimensional carbon nanotubes (1D), two-dimensional graphenes (2D) and various three-dimensional structures (3D) respectively. ${ }^{22-25}$ The $3 \mathrm{D}$ carbon based nanostructures such as 3D graphene based composites and 3D porous carbons of high mechanical and structural stability, high electrical conductivity and large pore volume have been extensively studied. ${ }^{26-31}$ The hard template route has been used to synthesize various $3 \mathrm{D}$ 
carbon frameworks for energy applications..$^{32-34}$ In addition, these nanostructures could be used as electron acceptors in polymer based solar cells due to their high interfacial area.

Hollow carbon spheres (HCSs) contain graphite like structures in their carbon shells. Because of these features they have been used extensively in fuel cells, ${ }^{35,36}$ as catalysts support, ${ }^{37,38}$ and in supercapacitors. ${ }^{\mathbf{3 9}, 40}$ This is due to their large pore volume, high surface area and the ability to tailor the diameters of the carbon shells. These nanostructured materials have been synthesized by hydrothermal carbonization, ${ }^{\mathbf{4 1}}$ templating, ${ }^{\mathbf{4 2 , 4 3}}$ Kirkendall effect, Ostwald ripening and the galvanic replacement methods among others. ${ }^{44}$ A hard templating method offers the ability to modify surface properties of templates, to manipulate the morphology and structure of the final product and to use readily available precursors. ${ }^{45}$ The carbon shell thickness can be controlled by varying the surfactant to precursor ratio, ${ }^{46,47}$ the amount of the carbon source ${ }^{48}$ and the carbonization time. ${ }^{49}$ To date, the carbon shell of a HCS is generally retained in the synthesis strategies employed. However, studies have indicated that structural collapse of a HCS can occur to produce broken shell structures. ${ }^{49-51}$

Organic solar cell (OSC), devices that convert solar energy into electrical energy often use semiconducting polymers made from carbon. Carbon is cheap, readily available, easily processable and is hydrophobic. This latter property ensures its compatibility with organic polymers used in the active layer when common organic solvents are used to make solar cell devices. In a bulk heterojunction (BHJ), the active layer comprises of an interpenetrating network of the p-type donor (poly(3-hexyl-thiophene-2,5-diyl), P3HT) and an n-type acceptor ([6,6]-phenyl- $\mathrm{C}_{61}$-butyric acid methyl ester, $\mathrm{PCBM}$ ) respectively. The key component here is the fullerene that is a single layered spherical carbon material. Other hollow carbon nanostructures can also act as the electron accepting materials and be used to form a ternary blend of the active layer. In this approach metallic impurities in the carbon material are not present as HCS synthesis, unlike carbon nanotube synthesis, requires no catalyst. $^{52-58}$ These early studies indicated that a key feature was the graphitic carbon network. To further explore the role of graphitic carbon structures in solar cell devices the use of "collapsed" HCSs has been explored. This is overcomes the issue associated with large HCSs that can conform to the size of the typical active layer dimensions of the OSC device and can lead to shorting. Graphene based nanostructures have been mainly used as electrode materials in organic and dye sensitized solar cells. ${ }^{59-61}$ In contrast, carbon nanotubes have been employed in the active layer to improve the efficiency of photovoltaic devices but owing to their metallic character favor charge carrier recombination. ${ }^{62-65}$ To our knowledge, the use of open ended worm like carbon nanostructures to form an active layer composite in organic solar cells has to date not been reported.

In this report, carbon has been deposited on monodispersed and polydispersed silica templates in the presence of $\mathrm{Au}$ nanoparticles embedded in the silica to produce graphene-like layered structures (Au@HCS). Hollow carbon spheres with broken spherical shells were produced from small and monodispersed $\mathrm{SiO}_{2}$ spheres and unusual open ended worm like layered structures were made from polydispersed silica sphere templates. In essence, the conversion of spherical core shell materials to an open ended worm like carbon nanostructures (3D) with unique morphologies by a CVD nanocasting method (a hard template route). The effect of Stober sphere diameter, polydispersion and carbonization time on the morphology of the carbon spheres produced as well as the role of the Au nanoparticles and the polyvinylpyrrolidone (PVP) used to cap the Au particles were studied. The obtained wormlike carbon nanostructures and the broken hollow/deformed carbon structures were employed in a ternary blend active layer to fabricate an organic solar cell.

\section{Experimental}

\subsection{Starting materials}

Tetraethyl orthosilicate, TEOS (98\%, Aldrich), ammonium hydroxide, $\mathrm{NH}_{4} \mathrm{OH}$ (25\% Fluka), ethanol (Merck 96\%) and deionized water were used as reagents for the synthesis of the silica spheres. Hydrofluoric acid, (HF; 40\%, Associated Chemical) was used for silica removal, and toluene (Aldrich) was used as a carbon source. Chloroauric acid, $\mathrm{HAuCl}_{4} \cdot 3 \mathrm{H}_{2} \mathrm{O}(99.99 \%$, Aldrich), polyvinylpyrrolidone, PVPK30 ( $M_{\mathrm{w}} 40$ 000, Aldrich), and trisodium citrate dihydrate were used as reagents for the synthesis of gold nanoparticles.

\subsection{Synthesis of silica spheres and hollow carbon spheres (HCSs)}

Monodispersed $\mathrm{SiO}_{2}$ spheres were synthesized by mixing $90 \mathrm{~mL}$ of ethanol, $63 \mathrm{~mL}$ of distilled water and $5 \mathrm{~mL}$ of $\mathrm{NH}_{4} \mathrm{OH}$ and the solution stirred for ten minutes. Then $16 \mathrm{~mL}$ of TEOS was added rapidly and the mixture stirred for 1 hour. In contrast, polydispersed $\mathrm{SiO}_{2}$ spheres were obtained by adding $2 \mathrm{~mL}$ of TEOS slowly to ethanol $(40 \mathrm{~mL})$ and $2 \mathrm{~mL}$ of $\mathrm{NH}_{4} \mathrm{OH}$ and the mixture allowed to stir for $1 \mathrm{~h}$. The solutions were centrifuged at 4500 rpm for 20 minutes and the product dried at $80{ }^{\circ} \mathrm{C}$ for 12 hours. Carbonization of both the monodispersed and polydispersed $\mathrm{SiO}_{2}$ spheres was carried out by a bubbling method using toluene as the carbon source and argon as the carrier gas in a chemical vapor deposition reactor for $1 \mathrm{~h}, 2 \mathrm{~h}$ and $4 \mathrm{~h}$ respectively $^{66}$ (Table 1). The carbonized silica was then etched with $10 \% \mathrm{HF}$ for 24 hours at room temperature and dried to give the hollow carbon spheres.

\subsection{Synthesis of Au nanoparticles}

$\mathrm{HAuCl}_{4} \cdot 3 \mathrm{H}_{2} \mathrm{O}(0.01 \mathrm{M}, 5 \mathrm{~mL})$ was stirred at reflux for 30 minutes and trisodium citrate dihydrate $(50 \mathrm{~mL}$ of $0.01 \mathrm{M})$ was added to the $\mathrm{Au}$ solution and the mixture stirred for 30 minutes. Polyvinylpyrrolidone (PVP; $0.5 \mathrm{~g}$ ) was dissolved in $20 \mathrm{~mL}$ of distilled water and added dropwise to the $\mathrm{Au}$ solution and stirred at room temperature for 12 hours. Centrifugation at $12000 \mathrm{rpm}$ for 15 minutes gave a suspension of gold nanoparticles $(d=14$ $\pm 4 \mathrm{~nm}$ ) in solution (Fig. S1†). 
Table 1 Effect of carbonization time on the carbon shell thickness

\begin{tabular}{|c|c|c|c|}
\hline Starting $\mathrm{SiO}_{2}$ material & $\mathrm{SiO}_{2}(\mathrm{~nm})$ & $\begin{array}{l}\text { CVD carbonization } \\
\text { time }(\mathrm{h})\end{array}$ & $\begin{array}{l}\text { Carbon shell } \\
\text { thickness (nm) }\end{array}$ \\
\hline \multirow[t]{3}{*}{ Monodispersed $\mathrm{SiO}_{2}$} & $400-500$ & 1 & $12 \pm 5$ \\
\hline & & 2 & $38 \pm 8$ \\
\hline & & 4 & $47 \pm 10$ \\
\hline \multirow[t]{3}{*}{ Polydispersed $\mathrm{SiO}_{2}$} & $90-310$ & 1 & $8 \pm 2$ \\
\hline & & 2 & $10 \pm 3$ \\
\hline & & 4 & $32 \pm 8$ \\
\hline
\end{tabular}

\subsection{Synthesis of $\mathrm{Au} @ \mathrm{SiO}_{2}$ spheres}

Gold@silica spheres were synthesized using the conditions shown in Table 2. Gold nanoparticles $(2 \mathrm{~mL}, 0.00016 \mathrm{M})$ were mixed with $20 \mathrm{~mL}$ of ethanol and $0.5 \mathrm{~mL}$ of ammonia solution (25 wt\%). The solutions were stirred for 20 minutes and then 1 $\mathrm{mL}$ of TEOS was added rapidly and the solutions stirred separately for 30 minutes and 1 hour respectively. The two solutions were then centrifuged for 20 minutes at $3500 \mathrm{rpm}$ and the collected solids dried at $80{ }^{\circ} \mathrm{C}$ for 12 hours to give monodispersed $\mathrm{Au} @ \mathrm{SiO}_{2} \mathrm{~A}$ and $\mathrm{Au} @ \mathrm{SiO}_{2} \mathrm{~B}$ spheres respectively. Polydispersed $\mathrm{Au} @ \mathrm{SiO}_{2}$ particles were made by adding gold nanoparticles $(20 \mathrm{~mL})$ to $40 \mathrm{~mL}$ of ethanol and $2 \mathrm{~mL}$ of ammonia solution ( $25 \mathrm{wt} \%)$. The solution was stirred for 20 minutes and $2 \mathrm{~mL}$ of TEOS was added slowly and the solution stirred for 1 hour, centrifuged for 20 minutes at $3500 \mathrm{rpm}$ and the collected solid dried at $80{ }^{\circ} \mathrm{C}$ for 12 hours to give $\mathrm{Au} @ \mathrm{SiO}_{2} \mathrm{C}$.

\subsection{Synthesis of Au@hollow carbon structures (Au@HCSs)}

Au@hollow carbon spheres (Au@HCSs) were synthesized by carbonization of the synthesized $\mathrm{Au} @ \mathrm{SiO}_{2}$ spheres in a horizontal chemical vapor deposition reactor. In separate reactors, the three $\mathrm{Au} @ \mathrm{SiO}_{2}$ samples $(0.06 \mathrm{~g}$ ) were uniformly spread onto a quartz boat which was placed in the center of a quartz tube. The furnace was heated to $900{ }^{\circ} \mathrm{C}$ at $10{ }^{\circ} \mathrm{C} \mathrm{min}^{-1}$ under an $\mathrm{Ar}$ atmosphere (Ar, $200 \mathrm{sccm})$. Once the desired temperature was reached, $\operatorname{Ar}(200 \mathrm{sccm})$ was bubbled through toluene for $1 \mathrm{~h}$ for $\mathrm{Au} @ \mathrm{SiO}_{2} \mathrm{~A}$ and $\mathrm{Au} @ \mathrm{SiO}_{2} \mathrm{~B}$ and for $1 \mathrm{~h}, 2 \mathrm{~h}$ and $4 \mathrm{~h}$ for $\mathrm{Au} @ \mathrm{SiO}_{2} \mathrm{C}$

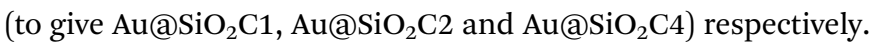
After this, the gas flow was stopped and the system was left to cool down to room temperature under an inert atmosphere (Ar, $200 \mathrm{sccm}$ ). The quartz boat was then removed from the reactor and the silica was removed with a $10 \%$ HF solution ( 24 hours) and after thorough washing with distilled water the product was dried at $80{ }^{\circ} \mathrm{C}$ for 12 hours to give the five Au@HCS samples (Table 3).

\subsection{Characterization}

The morphology of the synthesized gold nanoparticles, $\mathrm{Au} @ \mathrm{SiO}_{2}, \mathrm{Au} @ H C S s$, pristine $\mathrm{SiO}_{2}$ and the HCSs was ascertained by transmission electron microscopy (TEM) using a FEI Technai G2 spirit electron microscope operating at $120 \mathrm{kV}$. Graphitic domains in Au@HCS were determined using a JEOL JEM 2100 High Resolution TEM (JEOL, Japan) fitted with a LaB6 gun. Images were captured at $200 \mathrm{kV}$ using a Gatan Ultrascan camera (Gatan, USA). Samples were made by placing a droplet of suspended nanoparticles in ethanol on carbon coated grids and allowed to dry at room temperature. A Jobin Yvon T64000 Raman spectrometer equipped with an Ar ion laser (514.5 nm) and a laser power of $5 \mathrm{~mW}$ was used to establish the graphitic nature of the carbon found in the Au@HCSs and HCSs.

\section{Results and discussion}

\subsection{Silica spheres and hollow carbon spheres (HCSs)}

Stober silica spheres were synthesized by classical routes. ${ }^{67}$ The silica spheres were made using two different reactant concentrations and reaction times to give monodispersed and polydispersed $\mathrm{SiO}_{2}$ with different sizes as shown in Fig. S2. $\dagger$ Monodispersed $\mathrm{SiO}_{2}$ spheres $(400-500 \mathrm{~nm})$ were obtained when TEOS was added quickly while polydispersed $\mathrm{SiO}_{2}$ spheres (90$310 \mathrm{~nm}$ ) were obtained when TEOS was added slowly. A quick addition of TEOS results in the creation of nucleation sites at the same rate and time whereas a slow addition creates new nucleation site with each TEOS portion added, analogous to an interrupted particle growth mechanism. ${ }^{68,69}$ These spheres were carbonized with toluene for $1 \mathrm{~h}, 2 \mathrm{~h}$ and $4 \mathrm{~h}$ and the $\mathrm{SiO}_{2}$ was removed with HF to give HCSs (Table 1). The TEM images of the six different HCSs are shown in Fig. 1. It is noted that the HCSs were smaller in diameter than the $\mathrm{SiO}_{2}$ spheres due to the shrinkage of the silica spheres..$^{37,70}$

For all types of silica spheres used, carbon coverage on $\mathrm{SiO}_{2}$ was observed prior to etching. The carbon shell thickness increased with increasing carbonization time as shown in Table 1. After treatment of the $\mathrm{SiO}_{2} @ \mathrm{C}$ materials with $\mathrm{HF}$, it is seen that the carbon shells in monodispersed HCSs retained their spherical shape (Fig. 1a-c). In contrast, HCSs with deformed and interconnected carbon shells were obtained after treatment of the polydispersed $\mathrm{SiO}_{2} @ \mathrm{C}$ materials with HF (Fig. 1d and e). However, HCSs with complete carbon shells were obtained after $4 \mathrm{~h}$ carbonization of polydispersed $\mathrm{SiO}_{2}$ materials and $\mathrm{SiO}_{2}$ removal (Fig. 1f). Also to note: the carbon shell thickness of the polydispersed HCSs was thinner than that of the monodispersed HCSs. Though both mono and polydispersed $\mathrm{SiO}_{2}$ are chemically the same, $\mathrm{SiO}_{2}$ polydispersity was found to reduce

Table 2 Reaction conditions for the synthesis of $\mathrm{AuCSiO}$ spheres

\begin{tabular}{llllll}
\hline Description & Stirring time $(\mathrm{h})$ & Gold nanoparticle solution $(\mathrm{mL})$ & Ethanol $(\mathrm{mL})$ & Ammonia solution $25 \mathrm{wt} \%(\mathrm{~mL})$ & TEOS $(\mathrm{mL})$ \\
\hline $\mathrm{Au} @ \mathrm{SiO}_{2} \mathrm{~A}$ & 0.5 & 2 & 20 & 0.5 & 1 \\
$\mathrm{Au} @ \mathrm{SiO}_{2} \mathrm{~B}$ & 1 & 2 & 20 & 0.5 & 1 \\
$\mathrm{Au} @ \mathrm{SiO}_{2} \mathrm{C}$ & 1 & 20 & 40 & 2 & 2
\end{tabular}


Table 3 Effect of $\mathrm{SiO}_{2}$ sphere diameter in $\mathrm{AuQSiO}_{2}$ template on the carbon morphology

\begin{tabular}{|c|c|c|c|c|c|c|c|}
\hline Description & $\begin{array}{l}\text { Starting } \mathrm{SiO}_{2} \\
\text { material }\end{array}$ & $\mathrm{SiO}_{2}(\mathrm{~nm})$ & $\mathrm{Au}(\mathrm{nm})$ & $\begin{array}{l}\text { CVD carbonization } \\
\text { time }(\mathrm{h})\end{array}$ & Morphology & $\begin{array}{l}\text { Carbon shell } \\
\text { thickness (nm) }\end{array}$ & $\mathrm{Au}(\mathrm{nm})$ \\
\hline Au@HCSA & $\mathrm{Au} @ \mathrm{SiO}_{2} \mathrm{~A}$ & $80-110$ & $14 \pm 3$ & 1 & HCSs with broken shells & $8 \pm 3$ & $15 \pm 4$ \\
\hline Au@HCSC1 & $\mathrm{Au} @ \mathrm{SiO}_{2} \mathrm{C}$ & $90-300$ & $16 \pm 4$ & 1 & Layered graphene-like nanostructures & $13 \pm 2$ & $15 \pm 4$ \\
\hline Au@HCSC2 & $\mathrm{Au} @ \mathrm{SiO}_{2} \mathrm{C}$ & $90-300$ & $16 \pm 4$ & 2 & Open ended tube like nanostructures & $25 \pm 5$ & $16 \pm 4$ \\
\hline Au@HCSC4 & $\mathrm{Au} @ \mathrm{SiO}_{2} \mathrm{C}$ & $90-300$ & $16 \pm 4$ & 4 & Open ended tube like nanostructures & $38 \pm 10$ & $21 \pm 6$ \\
\hline
\end{tabular}

the number of carbonization layers. This could be attributed to the packing of polydispersed particles which restricts toluene infiltration between $\mathrm{SiO}_{2}$ spheres during carbon shell growth on $\mathrm{SiO}_{2}$.

\subsection{Au@SiO ${ }_{2}$ and Au@hollow carbon spheres}

$\mathrm{Au} @ \mathrm{SiO}_{2}$ was made by classical procedures by dispersing $\mathrm{Au}$ particles in a solution containing TEOS (Table 2). The sizes of encapsulated gold nanoparticles were almost the same in all the $\mathrm{Au} @ \mathrm{SiO}_{2} \quad$ spheres with a slight increase in size observed in $\mathrm{Au} @ H C S s$ obtained after carbonization and $\mathrm{SiO}_{2}$ removal (Table 3). Fig. 2 show the TEM images of $\mathrm{Au} @ \mathrm{SiO}_{2} \mathrm{~A}$ and $\mathrm{Au} @ \mathrm{SiO}_{2} \mathrm{~B}$ templates with their respective HCS morphologies obtained after $1 \mathrm{~h}$ carbonization. The longer reaction time $(1 \mathrm{~h}$ versus $0.5 \mathrm{~h}$ ) used in the formation of the template gave a larger HCS as expected. ${ }^{71,72}$ Carbonization of the smaller sized silica spheres (Au@SiO ${ }_{2} \mathrm{~A}$ ) produced broken hollow carbon spheres after etching away the $\mathrm{SiO}_{2}$ (Fig. 2c) while the large sized silica sphere (Au@SiO ${ }_{2} \mathrm{~B} ; 110-150 \mathrm{~nm}$ ) gave more unbroken spherical carbon shells after HF etching (Fig. 2d). Though, the thickness of the carbon shells was similar after $1 \mathrm{~h}$ carbonization time; the smaller HCSs were more prone to break during the etching procedures, due to the large strains induced by the larger
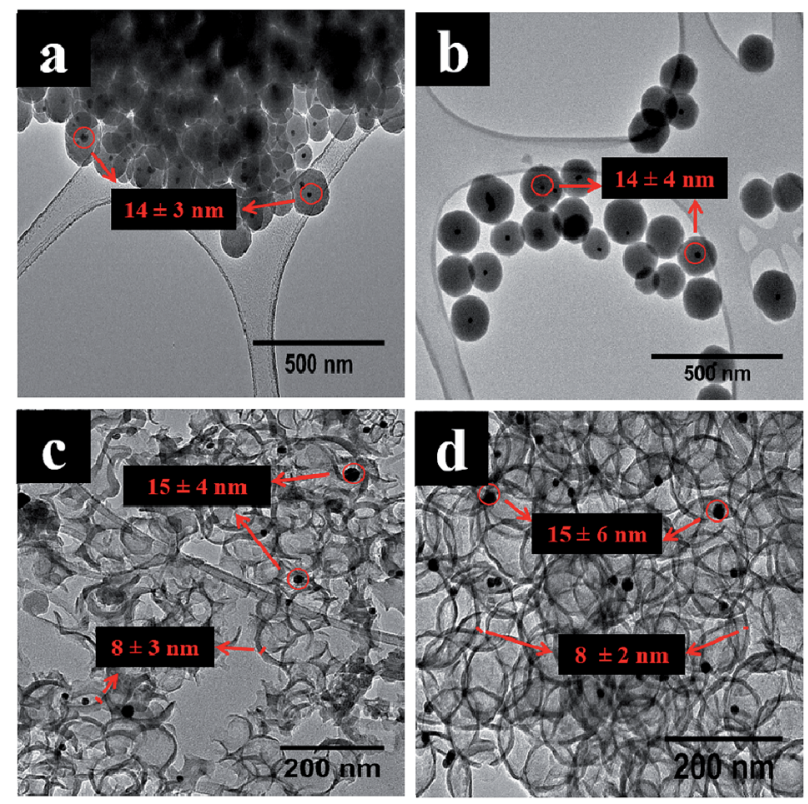

Fig. 2 TEM images of (a) $\mathrm{AuCSiO}_{2} \mathrm{~A}$, (b) $\mathrm{Au} @ \mathrm{SiO}_{2} \mathrm{~B}$ spheres before carbonization and (c) Au@HCSA and (d) Au@HCSB after $1 \mathrm{~h}$ carbonization time and $\mathrm{SiO}_{2}$ removal.
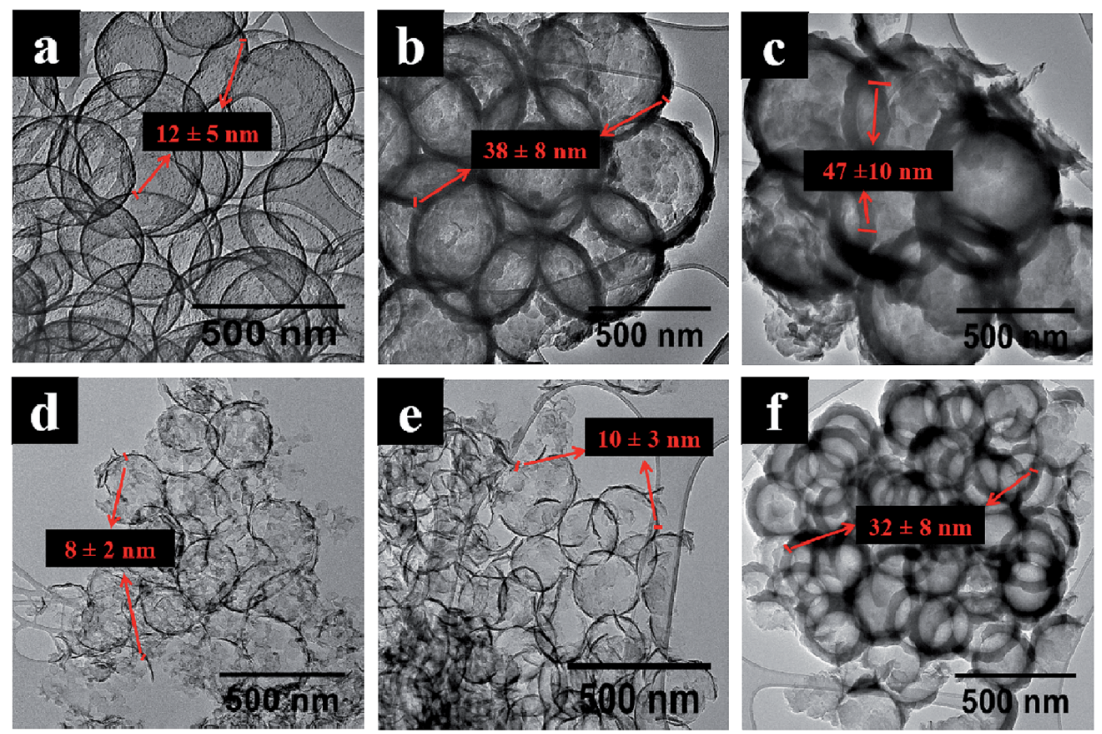

Fig. 1 TEM images of hollow carbon spheres; $(\mathrm{a}-\mathrm{c})$ from monodispersed $\mathrm{SiO}_{2}$ spheres and $(\mathrm{d}-\mathrm{f})$ from polydispersed $\mathrm{SiO}_{2}$ spheres after $(1 \mathrm{~h}, 2 \mathrm{~h}, 4$ h) carbonization times and $\mathrm{SiO}_{2}$ removal respectively. 
curvature which weaken upon $\mathrm{SiO}_{2}$ removal. Carbon shell thickness dependent collapse of $\mathrm{Au} @ \mathrm{SiO}_{2} \mathrm{~A}$ is thus unavoidable due to the smaller diameter size. ${ }^{50,51}$

Fig. 3a shows TEM images of polydispersed $\mathrm{Au} @ \mathrm{SiO}_{2} \mathrm{C}$ spheres after synthesis. After $1 \mathrm{~h}$ carbonization a thin carbon shell (11 $\pm 2 \mathrm{~nm}$ ) covering the silica (Fig. S3 $\dagger$ ) is formed which led to a layered carbon nanostructure (Fig. 3b) after HF etching. This contrasts with the morphologies found for Au@HCSA and Au@HCSB as the collapse led to large sheets of carbon shells instead of a hemispherical curved surface. The carbonization of
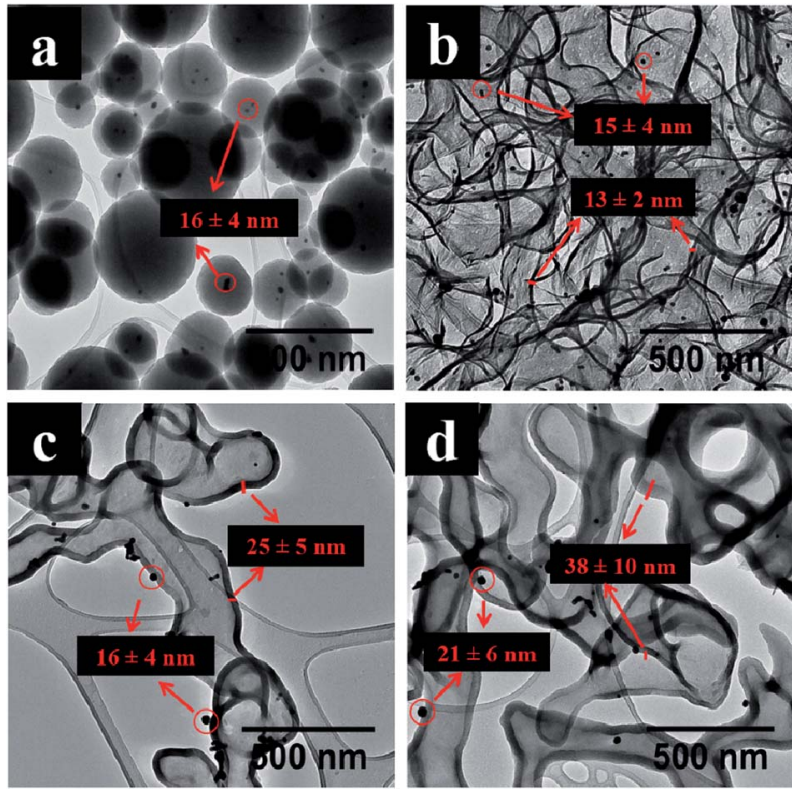

Fig. 3 TEM images of (a) AuaSiO ${ }_{2} \mathrm{C},(\mathrm{b}-\mathrm{d})$ Au@ HCSC obtained after (1 h, 2 h, 4 h) carbonization times and $\mathrm{SiO}_{2}$ removal respectively. silica spheres to give thin carbon shells occurred where the silica cores interconnected and breaching presumably occurred where the silica spheres intersected. A short carbonization time $(1 \mathrm{~h})$ produced a layered carbon nanosheet like morphology due to limited nucleation densities and surface coverage. Carbonization for longer times ( $2 \& 4 \mathrm{~h}$ ) led to the formation of long nanotube/worm like morphology (length $>500 \mathrm{~nm}$ ) (Fig. 3c and d). Table 3 shows that an increase in carbon shell thickness of Au@HCSC occurs with an increase in carbonization time.

Comparison of polydispersed Au@HCSC (Fig. 3) and polydispersed HCSs (Fig. 1) showed that in the absence of gold, HCSs with deformed and interconnected carbon shells were observed and no carbon nanosheet like morphology was noted. This implicates the presence of $\mathrm{Au}$ in the formation of the peculiar carbon structures. A more detailed analysis of Au@HCSC1 was obtained from HRTEM studies (Fig. 4). HRTEM images of the Au@HCSC1 revealed that the sample could be viewed as a carbon sheet (Fig. 4a) made of overlapping carbon layers formed from the extended array of hollow carbon structures (Fig. 4b). The extended array was in the form of discontinuous curved features portraying the wavy nature of the carbon sphere edge. ${ }^{73}$ The carbon structure appears to follow the curvature of the unzipped spheres (Fig. 4c). Further analysis of the 'film' indicates that the carbon 'shell' shows the presence of graphitic domains (Fig. $4 \mathrm{~d}$; $d$ interlayer spacing $=0.344 \mathrm{~nm}$ ) with short range ordering (Fig. 4e) over large parts of the carbon structure. The structure also indicates regions of amorphous carbon as confirmed by selected area electron diffraction (SAED) data (ESI Fig. S4 $\dagger$ ).

The factors responsible for the formation of the wormlike carbon structures are described below.

(i) Polydispersity. A possible cause of the growth of the wormlike and open ended graphene like structures is related to the $\mathrm{SiO}_{2}$ polydispersity. ${ }^{74-77}$ This is presumably due to the closer
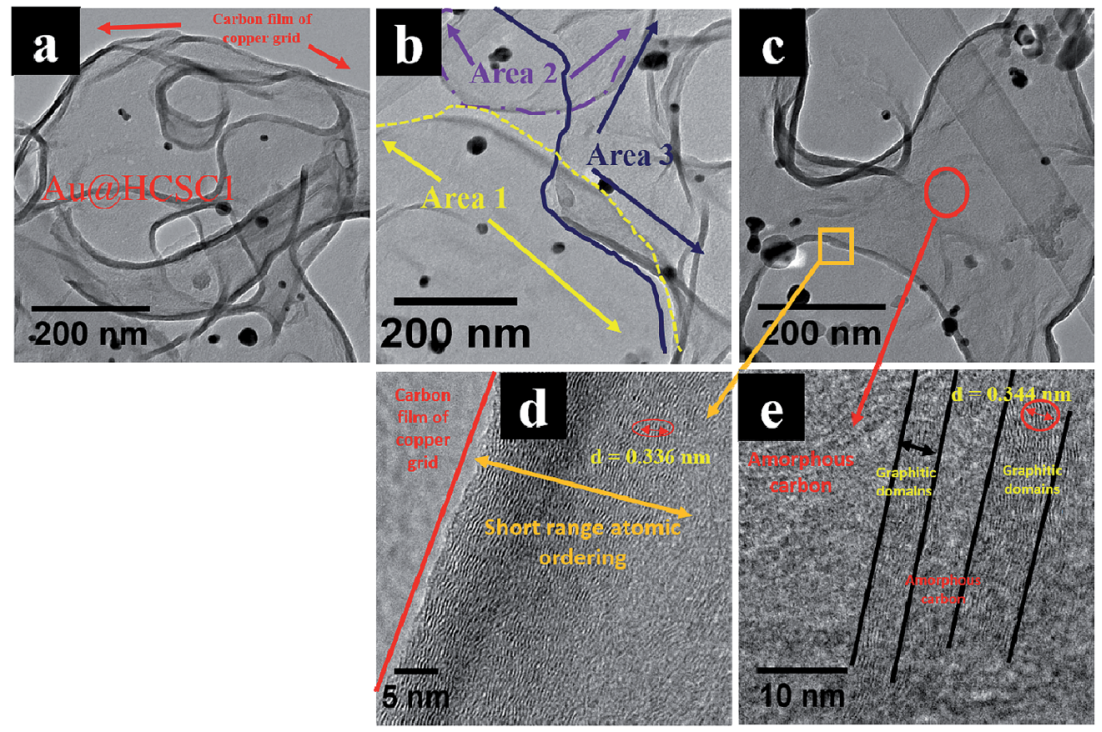

Fig. 4 HRTEM images of Au@HCSC1; (a) shows the carbon film of Au@HCSC1 and that of the copper grid, (b) shows three overlapping areas of the carbon sheet (black spots are Au particles), (c) shows a folded region and a sheet like region with magnified images of (d) folded region and (e) sheet like region. 
contact between the $\mathrm{SiO}_{2}$ spheres made possible when small and large $\mathrm{SiO}_{2}$ spheres are mixed. The carbon infiltrates less effectively between the mixed size spheres and this leads to the formation of thinner and hence weaker carbon structures. These are then more easily ruptured.

(ii) Carbonization time. The carbonization time determines the layer structure and wormlike structures after silica etching. The carbon shell thickness has an effect on the completeness of the HCS shell and a thin carbon wall is subject to high stresses which lead to fracture during HF etching. A long carbonization time results in higher nucleation density and diffusivity along the edges leading to a near uniform thickness of the wormlike structures. Continued carbonization results in further coverage and hence formation of thicker open ended and breached nanotube like structures.

(iii) Role of polyvinylpyrrolidone on carbon morphology. The presence of PVP (with a high molecular weight) on $\mathrm{SiO}_{2}$ synthesis has been reported to cause a broad silica size distribution. ${ }^{78}$ In this study, the volume of PVP used to make $\mathrm{Au} @ \mathrm{SiO}_{2} \mathrm{~A}$ and $\mathrm{Au} @ \mathrm{SiO}_{2} \mathrm{~B}$ (2 mL PVP) was less than that used to make $\mathrm{Au} @ \mathrm{SiO}_{2} \mathrm{C}$ (20 mL PVP) hence leading to modified $\mathrm{SiO}_{2}-$ $\mathrm{SiO}_{2}$ surface interactions during carbonization leading to different carbon deposits along the external $\mathrm{SiO}_{2}$ surfaces.

To confirm the influence of PVP on the morphology of the obtained worm like and open ended carbon nanostructures, polydispersed $\mathrm{SiO}_{2}$ spheres (Fig. S2b) and PVP $(20 \mathrm{~mL})$ were mixed together and stirred for 1 hour and 12 hours respectively (see ESI $\dagger$ ). The concentration of PVP was similar to that used in the synthesis of $\mathrm{Au} @ \mathrm{SiO}_{2} \mathrm{C}$ (for comparison purposes). Fig. S5a and $\mathrm{S} 5 \mathrm{~b} \dagger$ shows the silica spheres mixed with PVP before carbonization confirming the PVP surface coverage on silica. The polydispersed silica spheres mixed with PVP after $1 \mathrm{~h}$ stirring time, followed by carbonization and $\mathrm{SiO}_{2}$ removal produced worm like hollow carbon nanostructures (Fig. S5c $\dagger$ ). In contrast, a 12 hours stirring time, followed by carbonization and $\mathrm{SiO}_{2}$ removal gave broken hollow carbon spheres with a spherical morphology (Fig. S5d $\dagger$ ). The carbon shell thickness was $7 \pm 5 \mathrm{~nm}$ in the wormlike hollow structures and $9 \pm 7 \mathrm{~nm}$ for the broken/deformed hollow carbon spheres. The wormlike carbon nanostructures had a unique hierarchical structure with the coexistence of mesopores and macropores within the nonspherical cavity as shown by the nitrogen adsorption-desorption isotherm (ESI Fig. S9†).

In the study, $900{ }^{\circ} \mathrm{C}$ was used for carbonization of the silica. Mixing of silica with PVP results in the presence of hydrogen bonded PVP polymer chains on $\mathrm{SiO}_{2}$ that carbonizes on the silica surface. ${ }^{79-81}$ Some of the PVP was lost due to sublimation at the reaction temperature. The surface morphology is dependent on the amount of PVP bound on the silica surface. When a high concentration of PVP was used on $\mathrm{Au} @ \mathrm{SiO}_{2}$ and polydispersed $\mathrm{SiO}_{2}$ spheres, a thin carbon nanosheet and wormlike hollow structures were obtained.

(iv) Presence of Au. The HRTEM images of the Au@HCS indicate the HCSs have been broken and show folded edges of the carbon sheet on the planar structure (Fig. S6a $\dagger$ ). The folded edges have a higher interlayer spacing $(0.371 \pm 0.002 \mathrm{~nm})$ compared to the $d$ spacing of pure graphite $(0.335 \mathrm{~nm})^{\mathbf{8 2}}$
(Fig. S6b $\dagger$ ). This indicates an $11 \%$ strain in the carbon material around the $\mathrm{Au}$ and folding along the edges due to the carbon grown on the interconnected spheres. A difference in the curvature energies of thin carbon walls is thus expected for carbon in the presence/absence of Au particles. On removal of the silica, the carbon atoms can now relax and this leads to collapse/unzipping of the walls, leading to the formation of worm like carbon structures. The unzipping effect is not only related to the thinness of the carbon structure. If this was the case, the polydispersed HCSC1 (Fig. 1d) with a shell thickness of $8 \pm 2 \mathrm{~nm}$ would also be expected to form the worm like graphitic carbon structures. This is not seen. There is clearly less surface strain on the carbon wall after silica removal and hence HCSs with deformed and interconnected carbon shells are formed despite the presence of a thin carbon shell.

Fig. 5 shows a schematic diagram that summarizes the formation of the different carbon nanostructures for the Au@monodispersed and Au@polydispersed silica sphere templates. A small sized Au@monodispersed $\mathrm{SiO}_{2}$ sphere template results in Au@HCSs with breached shells while a large sized $\mathrm{Au} @ \mathrm{SiO}_{2}$ monodispersed sphere template gives Au@HCSs with complete shells. In contrast, the Au@polydispersed $\mathrm{SiO}_{2}$ sphere template gives graphene-like, wormlike and open ended tube like structures.

\subsection{Raman spectra of hollow carbon spheres and Au@hollow carbon spheres}

Table $\mathrm{S} 1 \uparrow$ shows the $I_{\mathrm{D}} / I_{\mathrm{G}}$ ratios of monodispersed and polydispersed HCSs. The corresponding Raman spectra for HCSs and Au@HCSs are shown in Fig. S7 and S8. $\dagger$ In all cases, a strong D band was exhibited between $1342 \mathrm{~cm}^{-1}$ and 1381 $\mathrm{cm}^{-1}$ due to the breathing mode of $\mathrm{sp}^{2}$ and $\mathrm{sp}^{3}$ carbon atoms. ${ }^{83,84}$ In addition, a $\mathrm{G}$ peak was observed between 1575 $\mathrm{cm}^{-1}$ and $1597 \mathrm{~cm}^{-1}$ which is a characteristic of bond stretching of $\mathrm{sp}^{2}$ atoms. An increase in structural defects with increasing carbonization time was observed as seen from $I_{\mathrm{D}} / I_{\mathrm{G}}$ ratios. This is expected as an increase in carbonization time increases the number of carbon atoms nucleating on the silica template leading to thicker carbon shells and thus more structural defects.Au@HCSA and Au@HCSC1 had fewer defects than Au@HCSB resulting in lower $I_{\mathrm{D}} / I_{\mathrm{G}}$ ratios (Table $\mathrm{S} 2 \dagger$ ). A

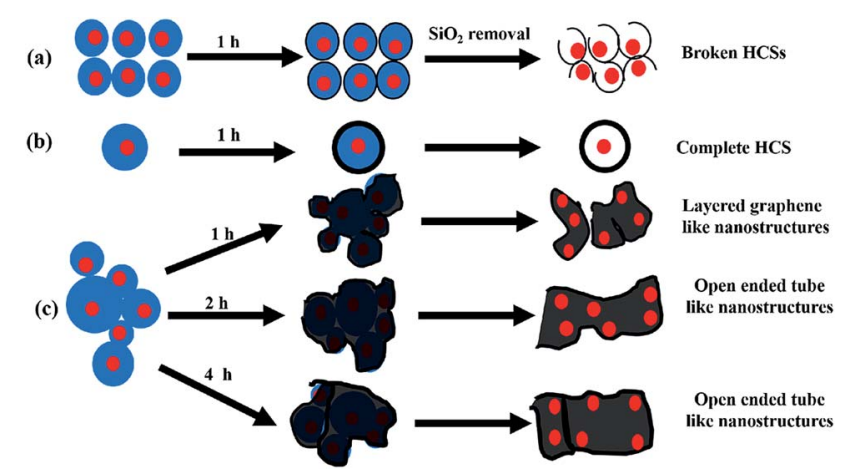

Fig. 5 Possible carbon nanostructure formation mechanism in (a) AuaSiO ${ }_{2} \mathrm{~A}$, (b) AuaSiO $2 \mathrm{~B}$ and (c) Au@ $\mathrm{SiO}_{2} \mathrm{C}$ respectively. 
comparison of the Raman spectra of polydispersed Au@HCSs and HCSs shows a broad band between $2700 \mathrm{~cm}^{-1}$ and 2900 $\mathrm{cm}^{-1}$ characteristic of a $2 \mathrm{D}$ band. The broadness of the peak indicates the presence of large defects with small graphitic domains. ${ }^{85,86}$ In Au@HCSC1, D and G bands were observed at $1370 \mathrm{~cm}^{-1}$ and $1590 \mathrm{~cm}^{-1}$ respectively with a $I_{\mathrm{D}} / I_{\mathrm{G}}$ ratio of 0.91 , indicating less graphitic character. A broad $2 \mathrm{D}$ band was observed in Au@HCSC1 showing the presence of both graphitic and non-graphitic domains in agreement with the HRTEM results.

\subsection{Application of worm like hollow carbon nanostructures and broken HCSs in organic solar cells}

The hollow carbon nanostructures (wormlike and broken HCSs) were mixed with P3HT and PCBM to form a ternary blend active layer (see ESI $\dagger$ ). The pristine active layer (PCBM:P3HT blend) had a thickness of $190 \pm 10 \mathrm{~nm}$. Fig. S11† shows the AFM images of P3HT:PCBM:wormlike carbon nanostructures and P3HT:PCBM:broken HCSs with a surface roughness of $81.5 \mathrm{~nm}$ and $91.8 \mathrm{~nm}$ respectively. A PCBM absorption peak was observed at $336 \mathrm{~nm}$ and $338 \mathrm{~nm}$ for P3HT:PCBM with broken HCSs and wormlike HCSs respectively (Fig. 6) ${ }^{87}$ The absorption intensity of P3HT peaks were observed at $517 \mathrm{~nm}$ and at 553 $\mathrm{nm} / 555 \mathrm{~nm}$, with a shoulder (\#) at $604 \mathrm{~nm} / 605 \mathrm{~nm}$ in the films containing broken HCSs/wormlike HCSs respectively due to P3HT interchain $\pi-\pi^{*}$ interactions. ${ }^{88,89}$ The absorption intensity of the film comprising of P3HT:PCBM:wormlike HCSs was higher than that made of P3HT:PCBM:broken HCSs due to enhanced scattering of light. An increase in absorption intensity in the wormlike HCSs led to an increased short circuit current density $\left(U_{\text {sc }}\right)$. The device performance is determined by the structural organization of the interpenetrating network,

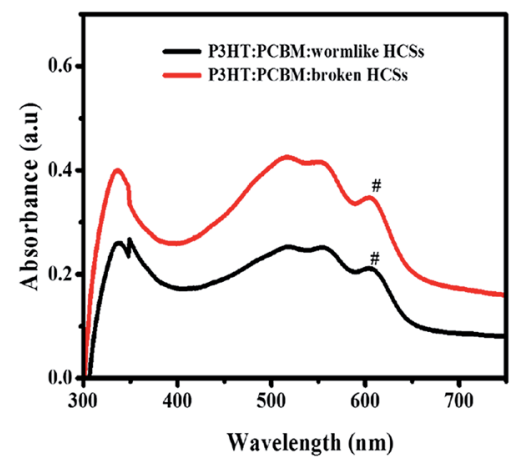

Fig. 6 UV-visible absorbance spectra of P3HT:PCBM:hollow carbon nanostructures films. interface energy and self-assembly of active layer composites. ${ }^{90,91}$ Theoretical studies and experimental results of organic photovoltaic devices have shown that P3HT chains can selfassemble to wrap around the carbon based nanostructures and change the conjugation length of the P3HT to modify the device charge transfer properties. ${ }^{91,92}$ It is proposed that the large interface area provided in the open ended worm like structure could increase the interconnectivity to the P3HT chains and thus, alter the charge transfer properties in the active layer composite.

Table 4 shows the current-voltage characteristics of the ternary blend active layer based organic solar cell under illumination and in the dark. An attempt to use hollow carbon spheres with a complete shell led to shorting of the photovoltaic devices due to their large diameter size. Hence, wormlike and broken HCSs were used. The current density of the device with wormlike HCSs is slightly higher than in the device with broken HCSs. This can be attributed to a reduced charge-transport distance, a slight increase in absorption intensity and less surface roughness in comparison to that of a device with broken HCSs. There was a slight increase in open circuit voltage $\left(V_{\text {oc }}\right)$ in the device with wormlike hollow carbon nanostructures which could be attributed to a change in the HOMO and LUMO energies of the active layer components. ${ }^{93-95}$ In addition, a possible charge carrier recombination is further corroborated by an S curve kink (see arrow in Fig. 7a) and by a high leakage current (Fig. 7b). The photovoltaic efficiency of the ternary solar cell fabricated using worm like structures was $0.11 \%$ while with broken hollow carbon spheres it was $0.14 \%$. While these values are low they show an improvement with reference to the unbroken HCSs (see Fig. 7). The increase in shunt resistance, open circuit voltage and fill factor (FF) in P3HT:PCBM:broken HCSs relative to that of the device with wormlike HCSs were responsible for the slight improvement in photovoltaic efficiency.
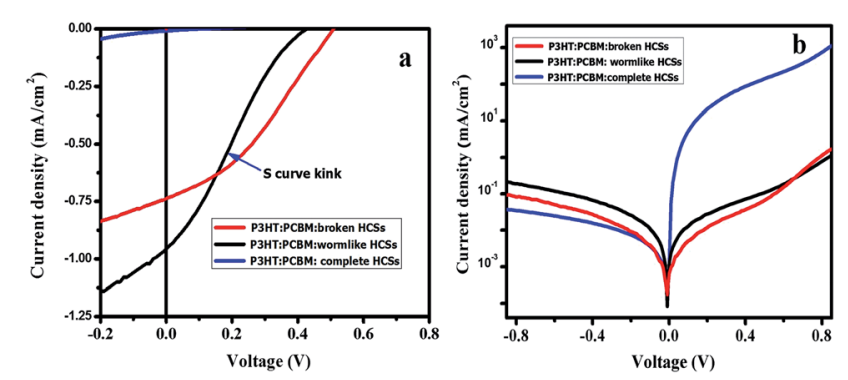

Fig. 7 P3HT:PCBM:hollow carbon nanostructures current-voltage $(J-V$ curves (a) under illumination and (b) semi log $J-V$ curves in the dark.

Table 4 Current-voltage characteristics of devices with P3HT:PCBM:wormlike HCSs and P3HT:PCBM:broken HCSs

\begin{tabular}{llllll}
\hline Description & $\begin{array}{l}J_{\mathrm{sc}} \\
\left(\mathrm{mA} \mathrm{cm}{ }^{-2}\right)\end{array}$ & $\begin{array}{l}V_{\mathrm{oc}} \\
(\mathrm{V})\end{array}$ & $\begin{array}{l}\text { Series resistance } \\
(\mathrm{ohms})\end{array}$ & $\begin{array}{l}\text { Shunt resistance } \\
(\mathrm{ohms})\end{array}$ & $\begin{array}{l}\text { FF } \\
(\%)\end{array}$ \\
\hline P3HT:PCBM:wormlike HCSs & 0.96 & 0.42 & $1.41 \times 10^{4}$ & $6.07 \times 10^{3}$ & 26.04 \\
P3HT:PCBM:broken HCSs & 0.73 & 0.50 & $5.95 \times 10^{3}$ & $2.14 \times 10^{4}$ & 0.11 \\
efficiency $(\%)$
\end{tabular}




\section{Conclusions}

This study provides insight into the effect of Au@polydispersed silica sphere templates and polydispersed $\mathrm{SiO}_{2}$ sphere templates towards the formation of hollow carbon nanostructures by a CVD nanocasting method, a study rarely performed. Au@HCSs and HCSs were successfully synthesized using a CVD nanocasting method with $\mathrm{Au@SiO}{ }_{2}$ and $\mathrm{SiO}_{2}$ spheres as templates. The size of the Au@SiO${ }_{2}$ and $\mathrm{SiO}_{2}$ templates used were found to play a key role in the synthesis of the hollow carbon spheres and nanostructures. Monodispersed and large sized $\mathrm{Au} @ \mathrm{SiO}_{2}$ spheres gave unbroken HCSs, whereas polydispersed $\mathrm{Au} @ \mathrm{SiO}_{2}$ spheres led to the formation of a range of hollow carbon nanostructures (thin carbon nanosheets and open ended nanotube like carbon). Modification of the surface chemistry of the polydispersed $\mathrm{SiO}_{2}$ using PVP was found to contribute to the worm like carbon nanostructures. Raman analysis confirmed the presence of the graphitized carbon in all the samples synthesized.

The Au@HCS core shell layered materials have been used for the generation of graphene like open structures. The polydispersed $\mathrm{SiO}_{2}$ sphere functionalized with PVP generated worm like hollow carbon structures. The application of the wormlike nanostructures in organic solar cells opens new studies into the electronic properties of these materials. However, functionality of the P3HT on the wormlike nanostructures through selfassembly could lead to higher exciton dissociation. Further studies to check the effect of PVP concentration and addition to $\mathrm{SiO}_{2}$ spheres on carbon sphere morphology to explore the formation and growth control of these carbon nanostructures and their application in organic solar cells with optimized parameters is underway.

\section{Acknowledgements}

We thank the NRF, the University of Witwatersrand and the DST-NRF Centre of Excellence in Strong Materials for financial support. We thank the CSIR Nanocentre (Dr J Wesley Smith), Pretoria for assistance with the HRTEM measurements.

\section{References}

1 Y. Byun and A. Coskun, Chem. Mater., 2015, 27, 2576-2583. 2 A. Narita, I. A. Verzhbitskiy, W. Frederickx, K. S. Mali, S. A. Jensen, M. R. Hansen, M. Bonn, S. De Feyter, C. Casiraghi, X. Feng and K. Müllen, ACS Nano, 2014, 8, 11622-11630.

3 A. Kouloumpis, K. Spyrou, K. Dimos, V. Georgakilas, P. Rudolf and D. Gournis, Frontiers in Materials, 2015, 2, 10. 4 Q. Kuang, S.-Y. Xie, Z.-Y. Jiang, X.-H. Zhang, Z.-X. Xie, R.-B. Huang and L.-S. Zheng, Carbon, 2004, 42, 1737-1741.

5 B. Hu, H. Ago, Y. Ito, K. Kawahara, M. Tsuji, E. Magome, K. Sumitani, N. Mizuta, K.-i. Ikeda and S. Mizuno, Carbon, 2012, 50, 57-65.

6 H. Kim, I. Song, C. Park, M. Son, M. Hong, Y. Kim, J. S. Kim, H.-J. Shin, J. Baik and H. C. Choi, ACS Nano, 2013, 7, 65756582.
7 Q. Wu, S. J. Jung, S. K. Jang, J. Lee, I. Jeon, H. Suh, Y. H. Kim, Y. H. Lee, S. Lee and Y. J. Song, Nanoscale, 2015, 7, 1035710361.

8 K. S. Kim, Y. Zhao, H. Jang, S. Y. Lee, J. M. Kim, K. S. Kim, J.-H. Ahn, P. Kim, J.-Y. Choi and B. H. Hong, Nature, 2009, 457, 706-710.

9 W. Liu, S. Kraemer, D. Sarkar, H. Li, P. M. Ajayan and K. Banerjee, Chem. Mater., 2014, 26, 907-915.

10 H. Ago, Y. Ito, N. Mizuta, K. Yoshida, B. Hu, C. M. Orofeo, M. Tsuji, K.-i. Ikeda and S. Mizuno, ACS Nano, 2010, 4, 7407-7414.

11 J. Wang, M. Zhu, R. A. Outlaw, X. Zhao, D. M. Manos and B. C. Holloway, Carbon, 2004, 42, 2867-2872.

12 M. Zhu, J. Wang, B. C. Holloway, R. A. Outlaw, X. Zhao, K. Hou, V. Shutthanandan and D. M. Manos, Carbon, 2007, 45, 2229-2234.

13 M. Zhu, J. Wang, R. A. Outlaw, K. Hou, D. M. Manos and B. C. Holloway, Diamond Relat. Mater., 2007, 16, 196-201.

14 L. Zeng, D. Lei, W. Wang, J. Liang, Z. Wang, N. Yao and B. Zhang, Appl. Surf. Sci., 2008, 254, 1700-1704.

15 Z. Wang, M. Shoji and H. Ogata, Appl. Surf. Sci., 2011, 257, 9082-9085.

16 V. Eswaraiah, S. S. Jyothirmayee Aravind and S. Ramaprabhu, J. Mater. Chem., 2011, 21, 6800-6803.

17 W. S. Hummers and R. E. Offeman, J. Am. Chem. Soc., 1958, 80, 1339.

18 A. K. Geim and K. S. Novoselov, Nat. Mater., 2007, 6, 183-191. 19 A. L. Higginbotham, D. V. Kosynkin, A. Sinitskii, Z. Sun and J. M. Tour, ACS Nano, 2010, 4, 2059-2069.

20 J. Li, S. Ye, T. Li, X. Li, X. Yang and S. Ding, Procedia Eng., 2015, 102, 492-498.

21 C. K. Chua, Z. Sofer, P. Šimek, O. Jankovský, K. Klímová, S. Bakardjieva, Š. Hrdličková Kučková and M. Pumera, ACS Nano, 2015, 9, 2548-2555.

22 H. Gleiter, Acta Mater., 2000, 48, 1-29.

23 V. V. Pokropivny and V. V. Skorokhod, Mater. Sci. Eng., C, 2007, 27, 990-993.

24 M. Terrones, A. R. Botello-Méndez, J. Campos-Delgado, F. López-Urías, Y. I. Vega-Cantú, F. J. Rodríguez-Macías, A. L. Elías, E. Muñoz-Sandoval, A. G. Cano-Márquez, J.-C. Charlier and H. Terrones, Nano Today, 2010, 5, 351-372. 25 J. N. Tiwari, R. N. Tiwari and K. S. Kim, Prog. Mater. Sci., 2012, 57, 724-803.

26 X.-L. Wu and A.-W. Xu, J. Mater. Chem. A, 2014, 2, 4852-4864. 27 H. Jiang, P. S. Lee and C. Li, Energy Environ. Sci., 2013, 6, 4153.

28 S. Mao, G. Lu and J. Chen, Nanoscale, 2015, 7, 6924-6943.

29 Z. Yang, S. Chabi, Y. Xia and Y. Zhu, Progress in Natural Science: Materials International, 2015, 25, 554-562.

30 L. Zhang and G. Shi, J. Phys. Chem. C, 2011, 115, 1720617212.

31 Z. Yang, C. Yan, J. Liu, S. Chabi, Y. Xia and Y. Zhu, RSC Adv., 2015, 5, 29397-29400.

32 C. Wu, S. Deng, H. Wang, Y. Sun, J. Liu and H. Yan, ACS Appl. Mater. Interfaces, 2014, 6, 1106-1112.

33 A. H. Lu and F. Schüth, Adv. Mater., 2006, 18, 1793-1805. 
34 H.-J. Peng, J. Liang, L. Zhu, J.-Q. Huang, X.-B. Cheng, X. Guo, W. Ding, W. Zhu and Q. Zhang, ACS Nano, 2014, 8, 1128011289.

35 C. Galeano, J. C. Meier, M. Soorholtz, H. Bongard, C. Baldizzone, K. J. J. Mayrhofer and F. Schüth, ACS Catal., 2014, 4, 3856-3868.

36 Z. Wen, Q. Wang, Q. Zhang and J. Li, Electrochem. Commun., 2007, 9, 1867-1872.

37 I. Nongwe, V. Ravat, R. Meijboom and N. J. Coville, Appl. Catal., A, 2013, 466, 1-8.

38 V. Ravat, I. Nongwe and N. J. Coville, ChemCatChem, 2012, 4, 1930-1934.

39 K. Wilgosz, X. Chen, K. Kierzek, J. Machnikowski, R. Kalenczuk and E. Mijowska, Nanoscale Res. Lett., 2012, 7, 1-5.

40 X. Chen, K. Kierzek, K. Cendrowski, I. Pelech, X. Zhao, J. Feng, R. J. Kalenczuk, T. Tang and E. Mijowska, Colloids Surf., A, 2012, 396, 246-250.

41 M. Li, Q. Wu, M. Wen and J. Shi, Nanoscale Res. Lett., 2009, 4, 1365-1370.

42 J. B. Joo, P. Kim, W. Kim, J. Kim, N. D. Kim and J. Yi, Curr. Appl. Phys, 2008, 8, 814-817.

43 P.-j. Cai and L. Feng, Mater. Chem. Phys., 2008, 108, 1-3.

44 H. C. Zeng, J. Mater. Chem., 2011, 21, 7511-7526.

45 A.-H. Lu, G.-P. Hao, Q. Sun, X.-Q. Zhang and W.-C. Li, Macromol. Chem. Phys., 2012, 213, 1107-1131.

46 B. Fang, J. H. Kim, M.-S. Kim, A. Bonakdarpour, A. Lam, D. P. Wilkinson and J.-S. Yu, J. Mater. Chem., 2012, 22, 19031-19038.

47 X. Chen, K. Kierzek, Z. Jiang, H. Chen, T. Tang, M. Wojtoniszak, R. J. Kalenczuk, P. K. Chu and E. Borowiak-Palen, J. Phys. Chem. C, 2011, 115, 17717-17724.

48 Y. Dai, H. Jiang, Y. Hu, Y. Fu and C. Li, Ind. Eng. Chem. Res., 2014, 53, 3125-3130.

49 F. Su, X. S. Zhao, Y. Wang, L. Wang and J. Y. Lee, J. Mater. Chem., 2006, 16, 4413-4419.

$50 \mathrm{X} . \mathrm{Xu}$ and S. A. Asher, J. Am. Chem. Soc., 2004, 126, 79407945.

51 P. M. Arnal, F. Schuth and F. Kleitz, Chem. Commun., 2006, 1203-1205, DOI: 10.1039/B517196B.

52 Y. Xia, Z. Yang and R. Mokaya, J. Phys. Chem. B, 2004, 108, 19293-19298.

53 C. Laurent, E. Flahaut, A. Peigney and A. Rousset, New J. Chem., 1998, 22, 1229-1237.

54 M. Kim, S. B. Yoon, K. Sohn, J. Y. Kim, C.-H. Shin, T. Hyeon and J.-S. Yu, Microporous Mesoporous Mater., 2003, 63, 1-9.

55 K. Wilgosz, X. Chen, K. Kierzek, J. Machnikowski, R. J. Kalenczuk and E. Mijowska, Nanoscale Res. Lett., 2012, 7, 269.

56 Y. Kanai and J. C. Grossman, Nano Lett., 2008, 8, 908-912.

57 Q. Sun, B. He, X.-Q. Zhang and A.-H. Lu, ACS Nano, 2015, 9, 8504-8513.

58 H.-J. Lu, Y. Li, L.-Q. Zhang, H.-N. Li, Z.-X. Zhou, A.-R. Liu, Y.-J. Zhang and S.-Q. Liu, RSC Adv., 2015, 5, 52126-52131.

59 H. Park, S. Chang, M. Smith, S. Gradečak and J. Kong, Sci. Rep., 2013, 3, 1581.
60 Z. Liu, P. You, S. Liu and F. Yan, ACS Nano, 2015, 9, 1202612034.

61 Y. Zhu, X. Meng, H. Cui, S. Jia, J. Dong, J. Zheng, J. Zhao, Z. Wang, L. Li, L. Zhang and Z. Zhu, ACS Appl. Mater. Interfaces, 2014, 6, 13833-13840.

62 I. Khatri, S. Adhikari, H. R. Aryal, T. Soga, T. Jimbo and M. Umeno, Appl. Phys. Lett., 2009, 94, 093509.

63 H. Derbal-Habak, C. Bergeret, J. Cousseau and J. M. Nunzi, Sol. Energy Mater. Sol. Cells, 2011, 95(1), S53-S56.

64 M. M. Stylianakis and E. Kymakis, Appl. Phys. Lett., 2012, 100, 093301.

65 G. Keru, P. G. Ndungu, G. T. Mola, A. F. Nogueira and V. O. Nyamori, J. Nanomater., 2016, 2016, 11.

66 Y. D. Xia and R. Mokaya, Adv. Mater., 2004, 16, 886-891.

67 W. Stöber, A. Fink and E. Bohn, J. Colloid Interface Sci., 1968, 26, 62-69.

68 V. Masalov, N. Sukhinina, E. Kudrenko and G. Emelchenko, Nanotechnology, 2011, 22, 275718.

69 K. Nozawa, H. Gailhanou, L. Raison, P. Panizza, H. Ushiki, E. Sellier, J. P. Delville and M. H. Delville, Langmuir, 2005, 21, 1516-1523.

70 J. H. Kim, B. Fang, M. Kim and J.-S. Yu, Catal. Today, 2009, 146, 25-30.

71 S. K. Park, K. D. Kim and H. T. Kim, Colloids Surf., A, 2002, 197, 7-17.

72 N. Jaramillo, C. Paucar and C. García, J. Mater. Sci., 2014, 49, 3400-3406.

73 X. H. Chen, F. M. Deng, J. X. Wang, H. S. Yang, G. T. Wu, X. B. Zhang, J. C. Peng and W. Z. Li, Chem. Phys. Lett., 2001, 336, 201-204.

74 J. T. G. Overbeek, Adv. Colloid Interface Sci., 1982, 15, 251277.

75 A. Van Blaaderen, J. Van Geest and A. Vrij, J. Colloid Interface Sci., 1992, 154, 481-501.

76 M. T. Harris, R. R. Brunson and C. H. Byers, J. Non-Cryst. Solids, 1990, 121, 397-403.

77 S.-L. Chen, P. Dong, G.-H. Yang and J.-J. Yang, Ind. Eng. Chem. Res., 1996, 35, 4487-4493.

78 Y. Chung, M. Jeon and C. Kim, Macromol. Res., 2009, 17, 3743.

79 V. M. Bogatyrev, N. V. Borisenko and V. A. Pokrovskii, Russ. J. Appl. Chem., 2001, 74, 839-844.

80 Y. K. Du, P. Yang, Z. G. Mou, N. P. Hua and L. Jiang, J. Appl. Polym. Sci., 2006, 99, 23-26.

81 F. Kooli, J. Chem., 2015, 2015, 8.

82 J. Luo, H. D. Jang and J. Huang, ACS Nano, 2013, 7, 14641471.

83 A. C. Ferrari, Solid State Commun., 2007, 143, 47-57.

84 F. Tuinstra and J. L. Koenig, J. Chem. Phys., 1970, 53, 11261130.

85 A. C. Ferrari and D. M. Basko, Nat. Nanotechnol., 2013, 8, 235-246.

86 A. Jorio, ISRN Nanotechnol., 2012, 2012, 16.

87 J. Liu, S. Shao, H. Wang, K. Zhao, L. Xue, X. Gao, Z. Xie and Y. Han, Org. Electron., 2010, 11, 775-783. 
88 N. Kiriy, E. Jähne, H.-J. Adler, M. Schneider, A. Kiriy, G. Gorodyska, S. Minko, D. Jehnichen, P. Simon, A. A. Fokin and M. Stamm, Nano Lett., 2003, 3, 707-712.

89 H. Sirringhaus, P. J. Brown, R. H. Friend, M. M. Nielsen, K. Bechgaard, B. M. W. Langeveld-Voss, A. J. H. Spiering, R. A. J. Janssen, E. W. Meijer, P. Herwig and D. M. de Leeuw, Nature, 1999, 401, 685-688.

90 I. Botiz and N. Stingelin, Materials, 2014, 7, 2273.

91 C. Yang, J. G. Hu and A. J. Heeger, J. Am. Chem. Soc., 2006, 128, 12007-12013.
92 M. Bernardi, M. Giulianini and J. C. Grossman, ACS Nano, 2010, 4, 6599-6606.

93 I. Lange, J. Kniepert, P. Pingel, I. Dumsch, S. Allard, S. Janietz, U. Scherf and D. Neher, J. Phys. Chem. Lett., 2013, 4, 3865-3871.

94 S. Günes, H. Neugebauer and N. S. Sariciftci, Chem. Rev., 2007, 107, 1324-1338.

95 C. J. Brabec, A. Cravino, D. Meissner, N. S. Sariciftci, T. Fromherz, M. T. Rispens, L. Sanchez and J. C. Hummelen, Adv. Funct. Mater., 2001, 11, 374-380. 